\title{
Celebrity Endorsement Problem on Social Media: Formulation, Analysis and Recommendation Algorithm
}

\author{
Lv Hai-xia $^{1}$, Yu Guang ${ }^{1}$ and Wu Gang ${ }^{2}$ \\ ${ }^{1}$ School of management, Harbin Institute of Technology, Harbin, Heilongjiang, China \\ ${ }^{2}$ Network \& information center, Harbin Institute of Technology, Harbin, \\ Heilongjiang, China \\ hattielv@hotmail.com,yug@hit.edu.cn,wugang@hit.edu.cn
}

\begin{abstract}
In this paper, a new matching recommendation algorithm is proposed to help enterprises find one or more proper celebrities from social media for their product endorsement. The fans group of a celebrity, his impaction value in the social media, as well as the matching degree between the celebrity and the product are selected to measure a celebrity. The attribute similarities between target customers of the product and fans of the celebrity are calculated via the Pearson similarity formula. Then, considering the impaction value of the celebrity and the matching degree of the celebrity and the product which can be accessed on the website or usually available from the enterprise, an evaluation index is proposed. We use some data from Sina Micro-blog, which is the most popular social media platform in China, to show the effectiveness of our proposed matching recommendation algorithm. Moreover, the analysis shows that a particular celebrity may suitable to endorse different product online and off-line.
\end{abstract}

Keywords: Celebrity endorsement, social media, Micro-blog, Recommendation Algorithm

\section{Introduction}

Endorsements are a common tool among manufacturers of retail products. One of the most important reasons to using endorsements is credibility and trust. Spokesperson is a broad concept, refers to the for-profit or non-profit for the enterprise or organization target and transmission services of special person [1]. Celebrity endorsement is a form of brand or advertising campaign that involves a well-known person using their fame to help promote a product or service. Manufacturers of perfumes and clothing are some of the most common business users of classic celebrity endorsement techniques, such as television ads and launch event appearances, in the marketing of their products [2].

There are a number of reasons why celebrity endorsements in advertising are so common. A celebrity endorsement can help build trust amongst current and potential customers, increase the chances of the brand being remembered, and attract new type of audiences. Endorsements also may increase the consumer's desire for a product. This is often achieved by implying that the particular celebrity is successful, talented, or attractive at least partly because of the product. Many people hold certain celebrities in high regard, thus an endorsement of a product instantly increases the amount of trust the consumer has in the brand. Another important reason why celebrity endorsements are so common in advertising is brand recall. There are a huge number of products being marketed to consumers all the time, so it is essential for a brand to find a way to stand out in the crowd and be remembered. If a customer sees an advertisement involving his or her favorite celebrity endorsing a particular 
product, then his or her chances of remembering that product will be greatly increased [3]. Many studies show strong support for the use of celebrity endorsements, arguing that celebrities help make brands recognizable and create a positive brand attitude [4], enhance the likelihood of purchase [5], foster brand loyalty, and positively impact word-of-mouth [6]. Moreover, these credible endorsers can produce more favorable attitudes toward the advertisement [7-8] and intent to purchase the product [9-10]. The investigation of Bickart and Schindler [11] indicate that product information on online forums has greater credibility, is easier to relate to, and is more likely to evoke empathy with consumers than is the information on seller-designed websites.

In the past, celebrity endorsements mostly were used on traditional media such as Television, Newspaper, Radio, Magzines and so on, to find a suitable celebrity to endorse product was difficult due to lack of data, and contained only minimal information about each node. Fortunately, the rise of the Internet has changed this dramatically [18] on new media. Crutchfield D. think celebrity endorsement in the era of new media still push product [12]. As the new media, social media marketing can satisfy the business enterprise different marketing strategies, can effectively reduce the enterprise's marketing costs and can realize precise marketing to target user. It is a marketing method that really conforms to the demand of users [13]. Social media platforms, particularly in China, have great power on consumers' buying behavior. According to HP's research, top retweeted users in Sina Micro-blog focus more on amusement and lifestyles than top retweeted uses in twitter. Moreover, topics of celebrity in Sina Micro-blog have times more retweets than celebrity in twitter. Therefore, the marketing on social media become more and more important for enterprises in China. Sina released 2012 annual report, at the end of last year, Sina social media users has exceeded 500 million, up $74 \%$ year from a year earlier, and 46.2 million daily active users, up $82 \%$ from a year earlier [14]. Some enterprise use Micro-blog as a new advertising media, some of them use it as a new direct sales channel, and some of them realized the communication and interaction properties of Micro-blog, then start a word-of -mouth marketing, however Micro-blog marketing is still in a preliminary stage. Celebrity endorsement is used in Micro-blog only in recent years, and rarely mentioned in the literature. Since the audience of celebrity in social media and traditional media is different, the product of celebrity endorsement is different. For example, most endorsement of Wu Qilong, who is a celebrity, relates to male product, while social media shows, $88.4 \%$ of his fans are female [17]. That means the endorsement of WU on social media maybe not still fit for the product which he endorsed in traditional media. Furthermore, the consistency of celebrities and his fans to some extent and the similarity of the celebrity fans and the target customers provide options for celebrity products.

In the article of Goeldi A. who has measured the value of advertising through the analysis of the content of social media [15]. Crumpler R and Parsons T. Provides a way to use social media to get the conversation, and make use of the method to analysis the target of advertisement ${ }^{[16]}$. Although many literatures studied the social media marketing, but didn't points out clearly how to use social media to select a celebrity, or a precise analysis of celebrity endorsement. Currently, the method to determine spokesperson is mainly using the evaluation of target customer to the alternative spokesperson, which is selected by questionnaire. Questionnaire statistical quantity and the precision is limited. Social media closely linked celebrities and fans together. This group has their common attributes and features, the use of this feature for marketing can achieve the purpose of precision marketing. This article combined with the applications of recommendation algorithm, recommend celebrity for the enterprise on social media by calculating the attribute similarity between target customers and celebrity fans to reduce the cost and improve the efficiency of product endorsements for enterprises by using the greater amount of data from social media. Then 
find the best advertising time through estimating the time distribution of celebrity fans activity, and maximized the positive effect or minimized the negative effect to the products during the endorsement course of celebrity. In addition, this paper also found the feature that the same product in a social media or out of social media match the different celebrity.

The rest of the paper is organized as follows: in Section 2, the celebrity endorsement recommendation algorithms are provided. The proposed algorithm is proposed in Section 3. In section 4, we discuss the problems of optimal advertising time determination and how to deal with emergencies. In Section 5, some experiments are given to show the effectiveness of the proposed algorithm. Finally, we give some concluding remarks and future directions.

\section{Celebrity Endorsement in Social Media}

In this section, we propose a matching recommendation algorithm. The framework of the proposed algorithm is shown in Figure 1.

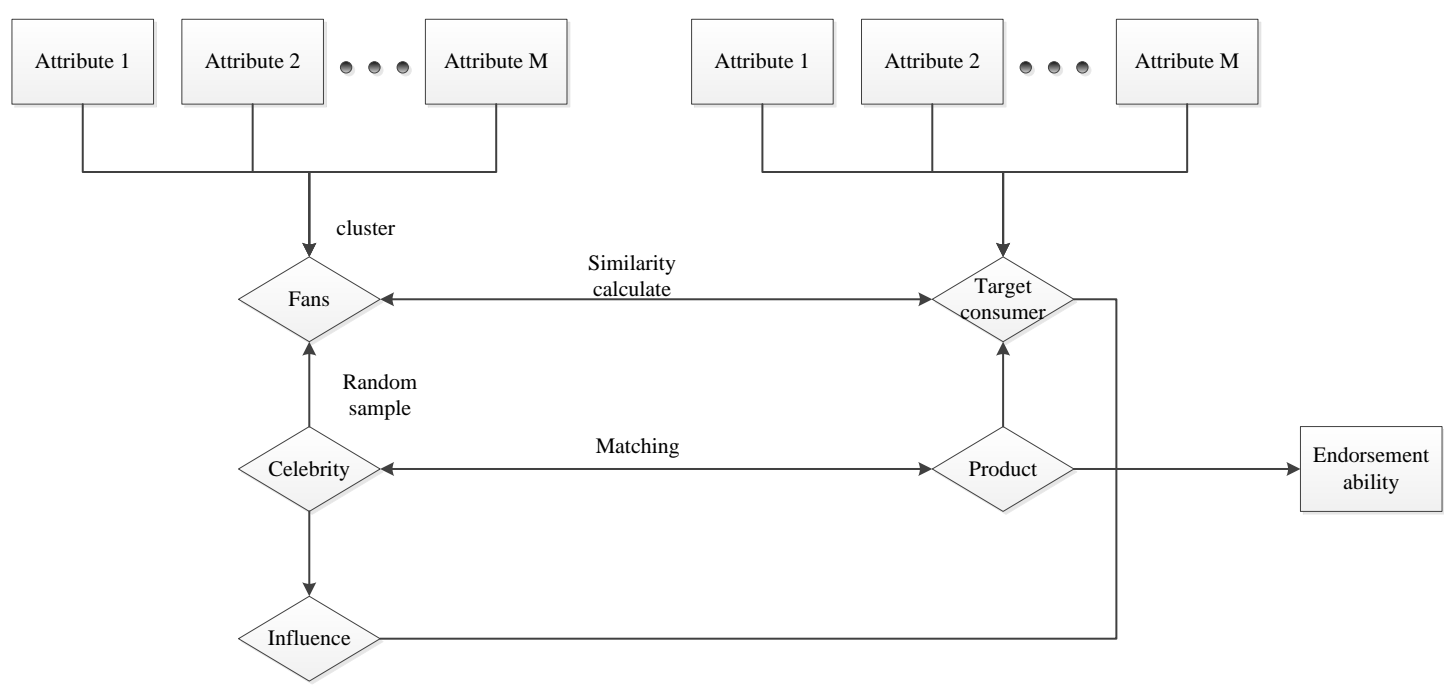

Figure 1. Conceptual Framework of the Proposed Model

First, we cluster the attribute of celebrity fans, then find the attributes of pre-set target customer of enterprise, and calculate the similarity of both above. Secondly, we calculate the matching degree between the candidate celebrity and the product, last we add the celebrity influence and summary three items of above to get the value of some celebrity endorsement of a product.

Analysis of celebrity fans attribute:

Generally, attribute of fans involves: ID, nickname, regional, gender, birth date, label, level, number of focus on, number of fans, number weibo, school, Personal profile, integral, interest, blogs, medal, credit information, etc.

The attribute of fans involves: ID, nickname, birth date, label, information of level, number of focus, number of fans, number of weibo, school, bio, integral, interest, blogs, medal information, credit information etc.

For instance, the topics of the fans of an ID which are interested in are shown in Figure 2. The gender ratio of male and female fans is shown in Figure 3. The area distribution of fans is shown in Figure 4. 
International Journal of $u$ - and e- Service, Science and Technology Vol.8, No.1 (2015)

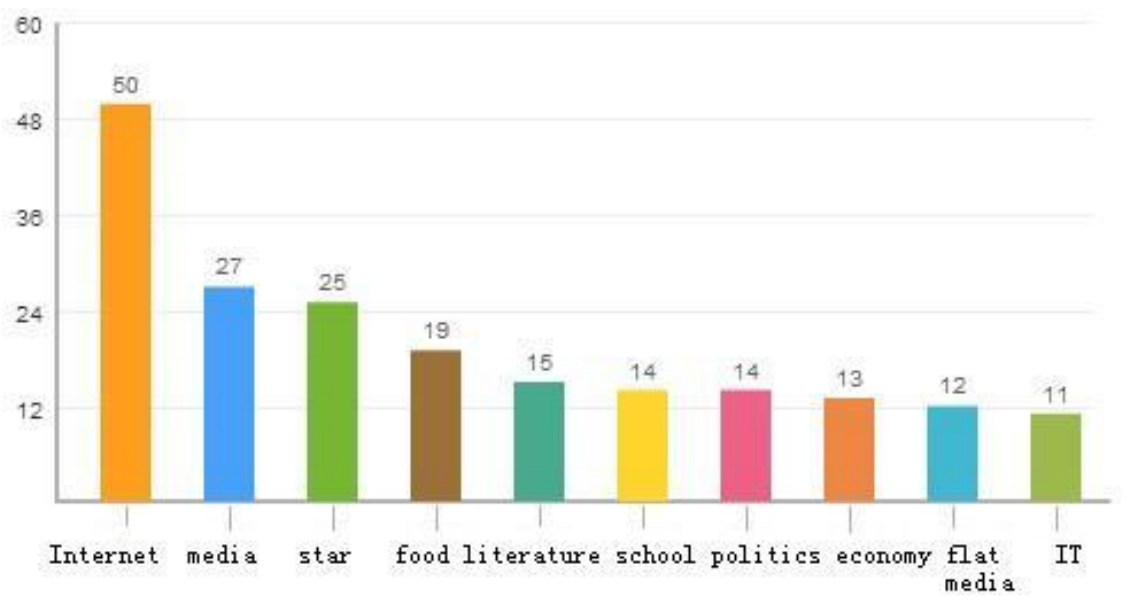

Figure 2. The Topics of Fans which are Interested in [22]

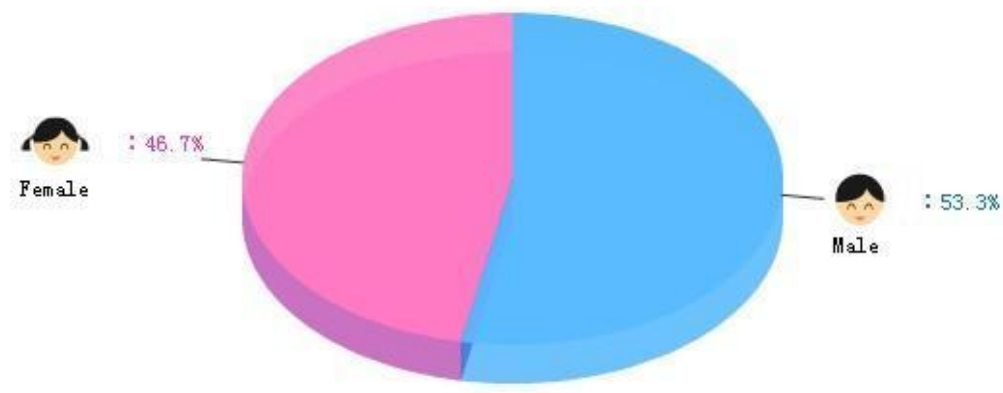

Figure 3. The Gender Ratio of Fans [22] 


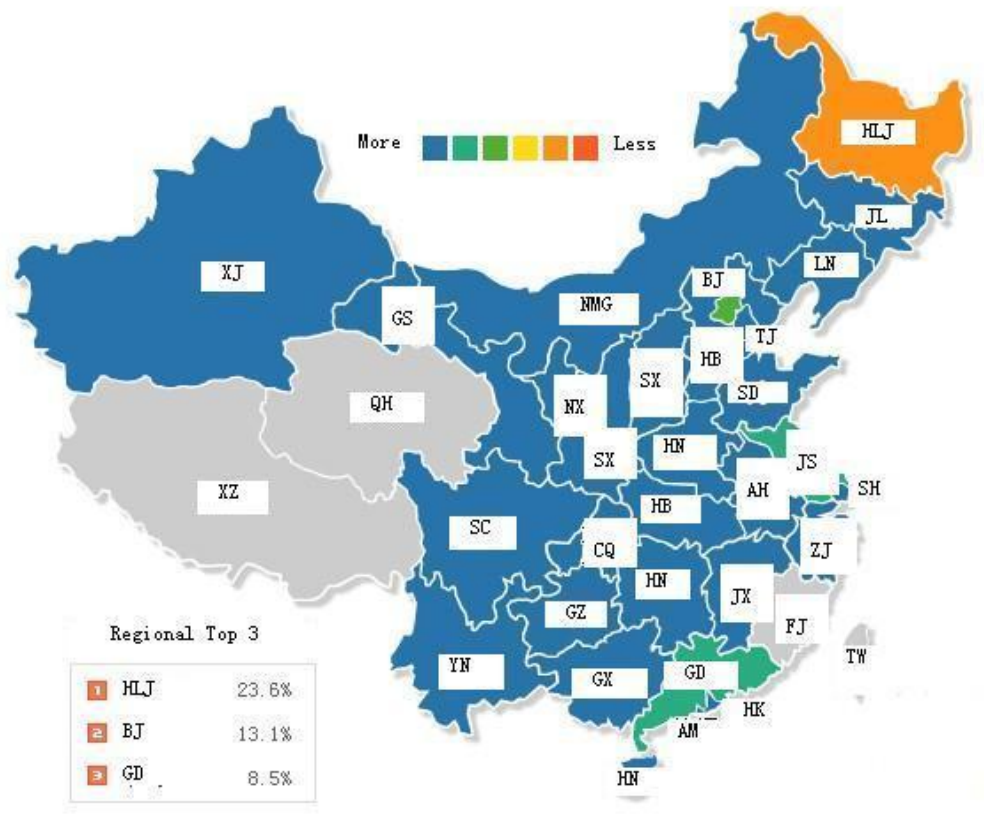

Figure 4. The Geographical Distribution of Fans [22]

In sum, firstly we need to determine the form and content of the fan's data to get the attributes of the fans of celebrity. We cluster fans in all kinds of attributes and extracted the most important attributes, for example hobbies, gender, age, region etc. Secondly, determine the attributes of the celebrity on social media. In third, we determine the attributes of the target customer of enterprise, and the required attributes of enterprise to celebrity such as attractiveness, effectiveness, recent performance etc.

Here, the fans of enterprise or enterprise seers brand is regard as the potential consumer., so the similarity of celebrity fans and the enterprise target customer determines whether the fans of celebrity is the target consumer or not. So J1 is the most important item and we give the biggest weight to $\mathrm{J} 1$, and let $\mathrm{a} 1=0.6$; Since celebrity influence determine the ability of activity, spread power and coverage of information, we regard it is the second important item for celebrity endorsement. We let a $2=0.3$; In the past literature, the matching between celebrities and products is controversial because some studies suggest they must be matched and others are opposed. So in this study we give this item the minimum weight, let a3=0.1.

\section{Matching Algorithm}

Although recommender systems can be traced back to the extensive work in the cognitive science, approximation theory, information retrieval, forecasting theories, and also have links to management science, and also to the consumer choice modeling in marketing, recommender systems emerged as an independent research area in the mid-1990's when researchers started focusing on recommendation problems that explicitly rely on the ratings structure [23].Recommender systems are personalized information filtering technology used to either predict whether a particular user will like a particular item (prediction problem) or to identify a set of $\mathrm{N}$ items that will be of interest to a certain user (top- $\mathrm{N}$ recommendation problem). 
According to different recommendation algorithm, the recommendation system can be divided into the following categories: collaborative filtering recommendation system; content-based recommendation system; hybrid recommendation system and the rise of userproduct network-based recommendation system recently [24].

The personalized recommendation system is through the establishment of binary relation between users and information products, mining each user potential object of interest by using selection process or similarity relation. Then personalized recommendation and its essence is information filtering. In this paper, we recommend the suitable celebrity endorsements for the enterprise based on the idea of this algorithm by calculating the similarity of a celebrity's fans and the target customers of product, the matching degree of celebrities and products and the influence of celebrity in the social media. The data we need to get including: (1) The label, ID, age, gender, region and level of celebrity fans; (2) The value of celebrity influence; (3) The attributes of products and target customers; (4) The requirements of enterprise to celebrity.

Calculated in four steps: (1) Determine the alternate celebrities, get a random sample of the celebrity fans, clustering the fans attribute, and then calculate the similarity of the fans between celebrity and product; (2) Calculate the matching of celebrity and products; (3) Calculate the alternative celebrity influence with the known top celebrity influence ratio; (4) Above three product to get the final result.

It has adopted many methods to calculate the similarity between users in collaborative filtering system. Most of these algorithms are based on scores of users to the products they like in common. Two of the most commonly used method is the Pearson correlation and included Angle cosine. Let $S=\left\{S_{1}, S_{2}, \ldots, S_{M}\right\}$ be the collection of all of the products, $r_{x}, s$ is the rating of the user $x$ to product $S, r_{y}$, is the rating of the user $y$ to product $S$, the product collection of the rating of the user $x$ and $y$ is: $S_{x y}=S_{x} \cap S_{y}$. The method based on graph theory doesn't need to calculate the $S_{x y}$ of all user $y$, but directly determine the nearest neighbor of $x$. The Pearson similarity of user $\mathrm{x}$ and $\mathrm{y}$ is defined as:

$$
\operatorname{sim}(x, y)=\frac{\sum_{s \in S_{x y}}\left(r_{x, s}-\bar{r}_{x}\right)\left(r_{y, s}-\bar{r}_{y}\right)}{\sqrt{\sum_{s \in S_{X y}}\left(r_{x, s}-\bar{r}_{x}\right)^{2} \sum_{s \in S_{x y}}\left(r_{y, s}-\bar{r}_{y}\right)^{2}}}
$$

The wimilarity of two vm-dementioned vectors $\mathrm{x}$ and $\mathrm{y}$ can be calculated by the following eauation

$$
\operatorname{sim}(x, y)=\cos (x, y)=\frac{x \cdot y}{\|x\|_{2} \times\|y\|_{2}}=\frac{\sum_{s \in S_{y}} r_{x, s} r_{y, s}}{\sqrt{\sum_{s \in S_{Y y}} r_{x, s}^{2} \sum_{s \in S_{Y y}} r_{y, s}^{2}}}
$$

Where $\mathrm{x} \cdot \mathrm{y}$ is the inner product of two vectors. Different system can adopt different similarity calculating method to make prediction score results as accurate as possible.

In this paper, we will use the included Angle cosine method. First, to determine the matching degree of attributes the fans' and the target customer attribute defined the $r_{x, s}$ as corresponding attributes value $S$ of celebrity fans $x, r_{y, s}$ as corresponding attributes value $S$ of the consumer $y$ of product. $S=\left\{S_{1}, S_{2}, \ldots, S_{M}\right\}$ is a collection of attributes for all; The overlap between $x$ and $y$ is $S_{x y}=S_{x} \cap S_{y}$; The similarity of celebrity fans and the target consumer of product is $\mathrm{J}_{1}$; The ratio of celebrity influence $\mathrm{A}$ and the highest $\mathrm{N}$ is $\mathrm{J}_{2}$; The degree of the celebrity and enterprise requirements is $\mathbf{J}_{3}$.

Then we have the following evaluation index which indicates the degree of celebrity endorsement of a suitable product, where $\mathrm{a}_{1}, \mathrm{a}_{2}, \mathrm{a}_{3}$ are the weights and satisfy: 


$$
\begin{gathered}
J=a_{1} J_{1}+a_{2} J_{2}+a_{3} J_{3} \\
a_{1}+a_{2}+a_{3}=1 \quad 0 \leq a_{1}, a_{2}, a_{3} \leq 1 \\
J_{1}=\operatorname{sim}(x, y)=\frac{\sum_{s \in S_{y y}} r_{x, s} r_{y, s}}{\sqrt{\sum_{s \in S_{x y}} r_{x, s}^{2} \sum_{s \in S_{y y}} r_{y, s}^{2}}} \\
J_{2}=\frac{A}{N}
\end{gathered}
$$

$\mathrm{J}_{3}=\{$ The compatibility of celebrity to face with the enterprise requirements $\}$

$$
J=a_{1} J_{1}+a_{2} J_{2}+a_{3} J_{3}
$$

Here we default the fans of enterprise or enterprise seers brand is the consumer of it, so the similarity of celebrity fans and the enterprise fans determine if the fans of celebrity is the target consumer. So $\mathbf{J}_{1}$ is the most important item and we give the biggest weight to $\mathrm{J}_{1}$, and let $a_{1}=0.6$; Since celebrity influence determine the ability of activity, spread power and coverage of information, we regard it is the second important item for celebrity endorsement. We let $\mathrm{a}_{2}$ $=0.3$; In the past literature, the matching between celebrities and products is controversial because some studies suggest they must be matched and others are opposed. So in this study we give this item the minimum weight, let $\mathrm{a}_{3}=0.1$.

\section{Optimal Advertising Time Determination and Emergency}

We counted the activity time distribution of celebrities on Sina Micro-blog. The hour distribution of Yao's tweets as follows:

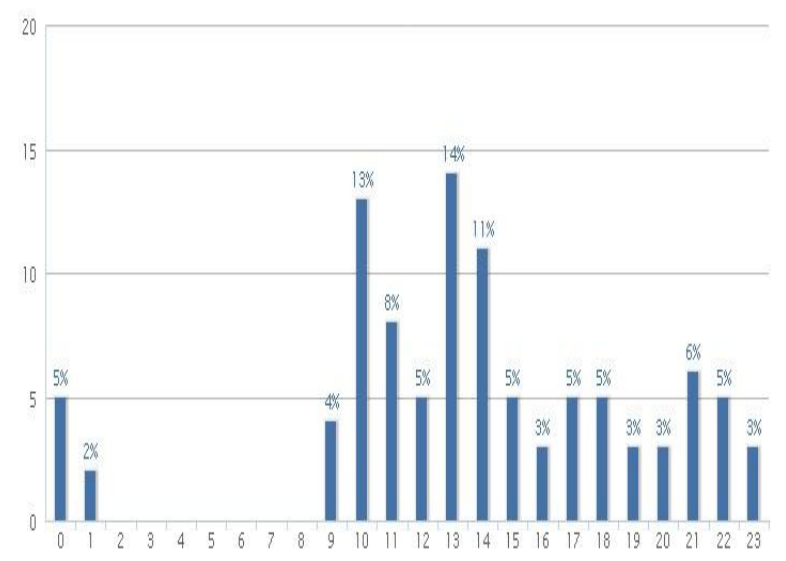

\section{Figure 5. The Vertical Axis Represents the Percentage for the Number of Micro-blog in This Hour of the Total Quantities of Micro-blog, and the Horizontal Axis Shows Hours [25]}

It can be seen from the activity time distribution of Yao is that the best time to advertise is at about 13 o'clock. Furthermore, the fans active rate is on the rise recently we can see from the fans active rate of history records given below. So it should be the appropriate time for advertising. 


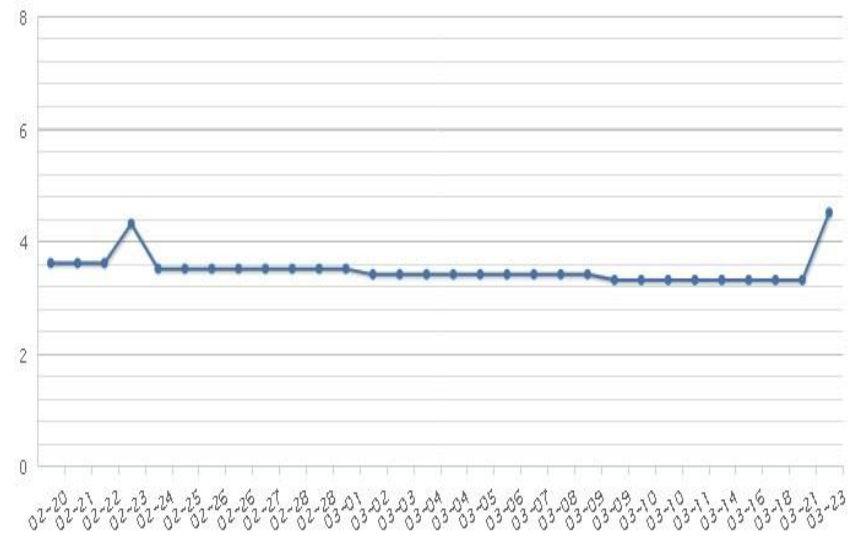

\section{Figure 6. The Fans Active Rate of History Records (The Vertical Axis Represents Active Fans Rate for the Date, and the Horizontal Axis Shows the Date.)}

Emergencies include two cases, one is positive, this may be because of Outstanding performance of celebrity in their areas, or celebrity privacy news such as get marry and have children, and so on. Enterprises should seize this period of media attention, improve product visibility, increase advertising.

One is negative, the sales of products that might directly have a negative impact, at the same time, the enterprise can choose to reduce exposure rate of product and celebrity at the same time, emphasize the positive image of the product or prove the reliability of the product indirectly with other methods.

This can sometimes work against the brand if the celebrity starts to receive negative press. Money et al. find that both Japanese and Americans view endorsed products more positively in the presence of self-oriented negative information, a possible suspension of the famous fundamental attribution error in human judgment [19]. Des et al. report on an experiment to test the impact of negative publicity on celebrity ad endorsements [20]. Miller et al. study the overarching goal of this article is to stimulate managers to think more deeply about the interconnections between their core company values, the athlete endorsers they select, and the ultimate effect of those decisions on their brands in the marketplace if things grow [21].

\section{Experiments and Discussions}

\subsection{The Case of Changan Automobile Endorsement}

We use Sina Micro-blog as an example, and we choose the Qilong $\mathrm{Wu}$, who is a Taiwanese singer and actor. Wu found fame in 1988, by joining the Taiwanese boy band, Little Tigers Team, performing alongside Alec Su and Julian Chen. Since then, his career has also expanded into film and television in Taiwan, Hong Kong and mainland China. As the alternative celebrity. The participants were 5000 fans of Qilong Wu and we screened 297 fans of level 3 or above as our research object. We got the following results through clustering the attributes of the fans:

The label of the fans and the ID they pay attention $S_{x 1}=\{\operatorname{music} 24.7 \%$, food $22.3 \%$, travel20.9\%, home $20.2 \%$, fashion shopping $11.8 \%\}$; The ages of his fan group $S_{x 2}=\{80 \mathrm{~s}$, 90 s $\}$; Fans sex ration $S_{x 3}=\{13.9 \%$ male, $86.1 \%$ female $\}$; Fans region $S_{x 4}=\{$ first-tier cities $50.34 \%$, second and third-tier cities $32.88 \%$; 
Since $\mathrm{Wu}$ successfully endorsement the car of Chang'an offline, we tried to test whether he is suitable for the car on social media. The target customer attributes of Chang'an car $S_{\mathrm{y} 1}=\{$ fashion, speed, film and TV, music, travel $\}$; The age $S_{\mathrm{y} 2}=\{26-35\}$; The sex ration $\mathrm{S}_{\mathrm{y} 2}=\{$ male $\}$; The region $\mathrm{S}_{\mathrm{y} 3}=\{$ second and third-tier cities $\}$.

$$
S_{x y}=S_{x} \cap S_{y}=\left\{\begin{array}{l}
\text { fashion, music, film, } T V, \text { travel } \\
26-35 \\
\text { male } \\
\text { second and third - tier cities }
\end{array}\right\}
$$

The influence of $\mathrm{Wu}$ is 1170 which is published on Sina statistical data, and the highest influence is 1322 of the celebrity Kai-fu Lee ${ }^{[26]}$. The influence algorithm of celebrity on Sina micro-blog as follow:

Influence $=\boldsymbol{a} \cdot$ activeness $+\boldsymbol{b}$ - propagatio $\mathbf{n}+\boldsymbol{c} \cdot$ coverage (8)

Because the successfully endorsement of $\mathrm{Wu}$ for Chang' an car in offline, we set $\mathrm{J}_{3}=1$.

The calculation results are as follows:

$$
r_{x}=\left\{\begin{array}{l}
0.63 \\
0.5 \\
0.139 \\
0.3288
\end{array}\right\}
$$

$$
r_{y}=\left\{\begin{array}{l}
0.8 \\
1 \\
1 \\
1
\end{array}\right\}
$$

Then, we have

$$
\begin{aligned}
& J_{1}=0.862 \\
& J_{2}=\frac{1170}{1322}=0.885 \\
& J_{3}=1 \\
& J_{W u}=0.763
\end{aligned}
$$

In the same way, we calculated the $\mathbf{J}_{1}$ and $\mathbf{J}_{2}$ of Kai-fu Lee and Jiong Hoo whose influence ranking in front of $\mathrm{Wu}$ and of Li-bo Zhou whose influence ranking behind $\mathrm{Wu} . \mathrm{J}_{3}$ is the requirements of enterprise to celebrity, we find a total of ten requirements of Chang'an car from the business plan [27]. Here, we gave the same weight of each item and let $J_{3}=1$, by the judge, the four selected representative conformity degree as Table 1.

Table 1. Requirements of Chang'an Car for Eelebrity

\begin{tabular}{|l|r|r|c|c|}
\hline The requirements of Chang'an car to celebrity & $\begin{array}{c}\text { W } \\
\mathbf{u}\end{array}$ & $\begin{array}{c}\text { Ho } \\
\mathbf{o}\end{array}$ & $\begin{array}{c}\mathbf{Z h} \\
\mathbf{o u}\end{array}$ & $\begin{array}{c}\mathbf{L} \\
\mathbf{e e}\end{array}$ \\
\hline He must be the idol of 26-35 years old people & 0.1 & 0.1 & 0.1 & $\begin{array}{c}0 . \\
05\end{array}$ \\
\hline He has a deep imprint in their growth & 0.1 & 0.1 & 0 & 0 \\
\hline He can dance and sing, his work is still popular & 0.1 & 0.0 & 0 & 0 \\
\hline His fans age in accordance with our sales people & 0.1 & 0.1 & 0.1 & 0. \\
\hline
\end{tabular}




\begin{tabular}{|c|c|c|c|c|}
\hline $\begin{array}{l}\text { His effect of word of mouth is a powerful rallying } \\
\text { point }\end{array}$ & 0.1 & 0.1 & 0.1 & \\
\hline $\begin{array}{l}\text { Star cooperate degree is high and acting plan can } \\
\text { also help products sales }\end{array}$ & 0.1 & 0.1 & 0.1 & \\
\hline He is a symbol of style and have time memory & 0.1 & 0.1 & 0 & 0 \\
\hline $\begin{array}{l}\text { He is a heavy weight star and have the market } \\
\text { effect }\end{array}$ & 0.1 & $5^{0.0}$ & 0.1 & \\
\hline $\begin{array}{l}\text { His independent personality and fashion } \\
\text { corresponds to the product and he is the best } \\
\text { appearance of the product }\end{array}$ & 0.1 & $5^{0.0}$ & 0.1 & \\
\hline $\begin{array}{l}\text { He can enhance brand appeal and have } \\
\text { internationalization }\end{array}$ & 0.1 & $5^{0.0}$ & 0.1 & 05 \\
\hline $\mathrm{J} 3$ & 11 & 0.8 & 0.7 & \\
\hline
\end{tabular}

The calculation results show that:

Therefore, we have

$$
\begin{aligned}
& J_{\text {Hоo }}=0.772 \\
& J_{\text {Zhou }}=0.456 \\
& J_{\text {Lee }}=0.387
\end{aligned}
$$

$$
\text { . } J_{\text {Hoo }}>J_{\text {Zhou }}>J_{\text {Lee }}
$$

The result show that the most suitable celebrity is Jiong Hoo to endorse the Chang'an car in the Sina Micro-blog, however Qilong Wu has endorsed Chang'an car off the social media. Even though Lee is the top one in the impaction list, and the male fans of Zhou is more than those of Wu's, the total matching degree between Lee, Zhou and the Chang'an car is not quite high. Therefore, they are not suitable to endorse this brand, which is also show that the result of the proposed algorithm is reasonable.

\subsection{The Case Study of L'oreal Endorsement}

In this section, we use Sina Micro-blog as an example, and we choose L'oreal and its series brand ID such as Lancome, Vichy, LiFuQuan and L'oreal man as the research object. We try to test:

(1)The spokesperson of L'orea offline have a Micro-blog ID, so if she still fit on social media.

(2)Whether the celebrity which is suitable for L'oreal is also suitable for the series brand of it.

(3)The best time for celebrity endorsement advertising.

In this section, we will have the following tests.

(1)We randomly selected 5000 fans from each ID of L'oreal, and we screened the fans of level 3 or above as our research object. Then we got the fans' attributes through the clustering as follows: 


$$
\begin{gathered}
r_{x 1}=\left\{\begin{array}{l}
a_{1} \\
a_{2} \\
a_{3} \\
a_{4} \\
a_{5}
\end{array}\right\} \\
r_{x 1}=\left(a_{1} a_{2} a_{3} a_{4} a_{5}\right)^{T}
\end{gathered}
$$

Where $a_{1}$ represents hobbies travel551, food 540, fashion 488, entertainment $483 ; a_{2}$ represents first-tier cities $46.28 \%$; $\mathrm{a}_{3}$ represents second-tier cities $45.19 \%$; $\mathrm{a}_{4}$ represents male $46 \%$; a 5 represents female $54 \%$.

Lee Bingbing has the highest influence on sina weibo of all spokespersons of L'orea offline, so we calculate the similarity between the fans of Lee and L'oreal on sina Micro-blog, and we got the attributes of the fans of Lee:

$$
\begin{gathered}
r_{y 1}=\left\{\begin{array}{l}
b_{1} \\
b_{2} \\
b_{3} \\
b_{4} \\
b_{5}
\end{array}\right\} \\
r_{y 1}=\left(b_{1} b_{2} b_{3} b_{4} b_{5}\right)^{T}
\end{gathered}
$$

Where $b_{1}$ represents hobbies: travel 344 , food 510 , fashion 428 , entertainments $221 ; b_{2}$ represents first-tier cities $36.41 \%$; $b_{3}$ represents second-tier cities $61.88 \%$; $b_{4}$ represents male $58.6 \% ; b_{5}$ represents female $41.5 \%$.

Calculating the similarity of $\mathrm{r}_{\mathrm{x} 1}$ and $\mathrm{r}_{\mathrm{y} 1}$, we can get

$$
\mathrm{J}_{1}=0.983 \text {. }
$$

The influence value of Lee is 925, the influence ratio with Lee Kaifu (The top influence celebrity of Sina Micro-blog) is 1322, then we can have

$$
\mathbf{J}_{2}=0.6997 \text {. }
$$

Since Lee has successfully endorsed for L'oreal offline, we regard the matching degree of Lee and L'oreal

$$
\mathrm{J}_{3}=1 \text {. }
$$

The value of Lee who as the endorsement of L'oreal on social media is

$$
\mathrm{J}_{\text {Lee }}=0.8997 \text {. }
$$

Next, we choose two female celebrities Yao Chen and Xie Na whose influence ranking in front of Lee on Sina Micro-blog to compare with Lee. Since the career of Yao is similar to Lee, we give the matching degree between Yao and L'oreal $\mathrm{J}_{3}=0.8$, and the career of Xie is as show hostess, we give the matching degree $J_{3}=0.5$. Then, it is easy to get the result as follows:

As it can be seen from the results

$$
\begin{aligned}
\mathrm{J}_{\mathrm{Xie}} & =0.930 \\
\mathrm{~J}_{\mathrm{Yao}} & =0.954 .
\end{aligned}
$$




$$
\mathrm{J}_{\text {Lee }}<\mathrm{J}_{\text {Xie }}<\mathrm{J}_{\text {Yao }} \text {, }
$$

which shows that the effect of endorsement different due to the changes of environment. We have reasons to believe that Yao is the suitable celebrity for L'oreal instead of Lee on social media.

To test (2), we calculate if Yao is the most suitable celebrity for the series brand of L'oreal by using the brand Biother as an example.

The results showed that:

$$
\begin{aligned}
& \mathrm{J}_{\mathrm{Ya}}=0.947, \\
& \mathrm{~J}_{\mathrm{Xie}}=0.944 .
\end{aligned}
$$

The difference is only $0.3 \%$ between Yao and Xie, thus it can be seen that although Yao is the most appropriate as a spokesperson for L'oreal, but the result is not obvious when compared Yao and Xie who is the best one for Biother. So we have reason to believe that the series brand of same enterprise may need different spokesperson.

Furthermore, there are men's cosmetics of L'oreal, so we compared Yao with Lee Kaifu and Hoo Jiong who are the male celebrities on sina Micro-blog to see which one is the most favorite celebrity for L'oreal man. Since the endorsement of L'oreal offline are all young men who are in the interpretation of industry with international influence, Lee Kaifu is an middle aged man as an information industry executive and computer science researcher, Hoo Jiong is a young man of Chinese famous anchor, so we gave the matching degree of Lee is 0.5 , of Hoo is 0.6 and of Yao is 0.4 as she is female. The result is:

$$
\begin{aligned}
& \mathrm{J}_{\text {Yao }}=0.899, \\
& \mathrm{~J}_{\text {Lee }}=0.924, \\
& \mathrm{~J}_{\mathrm{Hoo}}=0.940 .
\end{aligned}
$$

We can see from the result that Hoo is the favorite endorsement of L'oreal man. Thus we further confirm that the series brand of same enterprise need different face.

The quantitative results are given from the experiments of above: 1 . The celebrity may fit for endorsing different product in traditional media and social media. The enterprise must reconsider the problem of selecting celebrity in social media to fit for the marketing strategy. 2. The series brand of same enterprise may need different spokesperson. It is same as in traditional media. But the choose method is different.

\section{Remarks}

In this paper, we proposed a matching recommendation algorithm which can be used to help an enterprise to determine the celebrity who is more suitable for their product. The fans group of a celebrity, his impaction value in the social media and the matching degree between the celebrity and the product are required in the algorithm.

In the current work, we only use 5000 fans of an enterprise ID in each experiment to analysis their attribute, the amount of data is limited in this big data time. The main three factors we considered in the proposed algorithm, i.e., the fans group of a celebrity, his impaction value in the social media and the matching degree between the celebrity and the product have different affection on the index in the matching recommendation algorithm. Actually, proper weightings should be added to show the important considerations of the enterprise by using a more accurate method Future research work will focus on these issues.

\section{Acknowledgment}

The authors would like to show their appreciate to the National Natural Science Foundation of China(71171068), for their financial support, and to International Conference 
on Management Science and Engineering, for the valuable advices we get to complete this paper.

\section{References}

[1] http://baike.baidu.com/view/2279080.htm.

[2] http://www.businessdictionary.com/definition/celebrity-endorsement.html.

[3] http://www.wisegeek.org/what-is-the-effect-of-celebrity-endorsements-in-advertising.htm.

[4] R. E. Petty, J. T. Cacioppo and D. Schumann, "Central and peripheral routes to advertising effectiveness: The moderating role of involvement [J]", Journal of Consumer Research, vol. 10, (1983), pp. 135-146.

[5] H. H. Friedman and L. Friedman, "Endorser effectiveness by product type [J]", Journal of Advertising Research, vol. 19, (1979), pp. 63-71.

[6] A. J. Bush, C. A. Martin and V. D. Bush, "Sports celebrity influence on the behavioral intentions of generation Y [J]", Journal of Advertising Research, vol. 44, (2004), pp. 108-119.

[7] R. E. Goldsmith, B. A. Lafferty and S. J Newell, "The impact of corporate credibility and celebrity credibility on consumer reaction to advertisements and brands [J]", Journal of Advertising, vol. 29, (2000), pp. 43-54.

[8] B. Lafferty, R. E. Goldsmith and S. J Newell, "The dual credibility model: The influence of corporate and endorser credibility on attitudes and purchase intentions [J]", Journal of Marketing Theory and Practice, vol. 10, (2002), pp. 1-12.

[9] B. Lafferty and R. E. Goldsmith, "Corporate credibility's role in consumers' attitudes and purchase intentions when a high versus a low credibility endorser is used in the AD [J]", Journal of Business Research, vol. 44, (1999), pp. 109-116.

[10] R. Ohanian, “The impact of celebrity spokesperson's perceived image on consumers' intention to purchase [J]", Journal of Advertising Research, vol. 31, (1991), pp. 46-52.

[11] B. Bickart and R. M. Schindler, "Internet forums as influential sources of consumer information [J]", Journal of Interactive Marketing, vol. 15, (2001), pp. 31-40.

[12] D. Crutchfield, "Celebrity Endorsements Still Push Product: Why in the Era of Social Media, the Rewards Continue To Outweigh the Risks [J]", Ad Age, (2010).

[13] http://baike.baidu.com/view/3136291.htm.

[14] http://www.tj.xinhuanet.com/tt/2013-02/28/c_114836830.htm.

[15] A. Goeldi, "Website network and advertisement analysis using analytic measurement of online social media content: U.S. Patent, vol. 7, no. 974, 983, (2011), pp. 7-5.

[16] R. Crumpler and T. Parsons, "System and Method For Advertisement Targeting of Conversations in Social Media: U.S. Patent Application 12/264,168[P]. 2008-11-3.

[17] http://data.weibo.com/index/hotword?wid=10tj8AjHR.

[18] P. Domingos, "Mining social networks for viral marketing [J]", IEEE Intelligent Systems, vol. 20, no. 1, (2005), pp. 80-82.

[19] R. B. Money, T. A. Shimp and T. Sakano, "Celebrity endorsements in Japan and the United States: Is negative information all that harmful [J]?”, Journal of Advertising Research, vol. 46, (2006), pp. 113-123.

[20] D. Thwaites, B. Lowe, L. L. Monkhouse and B. R. Barnes, "The impact of negative publicity on celebrity ad endorsements [J]”, Psychology \& Marketing, vol. 29, no. 9, (2012), pp. 663-673.

[21] F. M. Miller and G. R. Laczniak, "The ethics of celebrity-athlete endorsement what happens when a star steps out of bounds [J]?”, Journal of Advertising Research, vol. 51, no. 3, (2011), pp. 499-510.

[22] http://data.weibo.com/mydata/fans/dna

[23] G. Adomavicius and A. Tuzhilin, "Towards the next generation of recommender systems [J]", IEEE Transactions on Knowledge and Data Engineering, vol. 17, (2005), pp. 734-749.

[24] J. Liu, T. Zhou and B. Wang, "The research progress of personalized recommendation system [J]", Progress in Natural Science, vol. 19, no. 1, (2009), (in Chinese).

[25] http://www.tfengyun.com/user.php?source=rank\&userid=1266321801

[26] http://data.weibo.com/top/help\#tag5.

[27] http://wenku.baidu.com/view/4ef7592d4b73f242336c5f8a.html. 


\section{Authors}

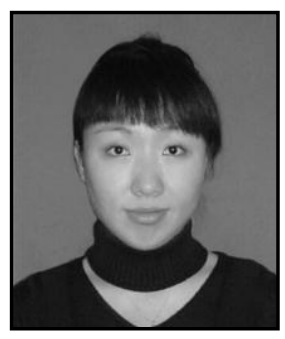

LvHai-xia, She got the Master Degree of Master of Business Administration in 2006 and Master of Public Administration in 2008. Now she is majoring in $\mathrm{PhD}$ of Management in Management Department from HIT. Her current research interests include different aspects of Social Media and Machine learning.

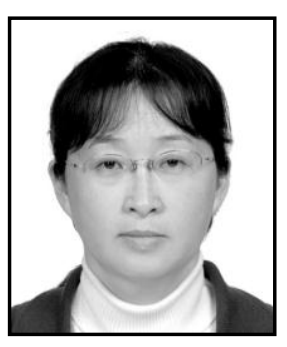

YuGuang, She got a Bachelor Degree (1985) and a Master Degree (1990) of Engineer in power engineering department of Harbin Institute of Technology(HIT). She got a $\mathrm{PhD}$ of Management science and Engineering in HIT in 2007. She has been a professor in College of Management, a graduate and doctoral tutor in Harbin Institute of Technology since 2008. She is a peer review of many SCI Journal, such as information Science journal, IEEE Transactions on Reliability, et al. Her current research interests include different aspects of Artificial Intelligence and Machine learning. 